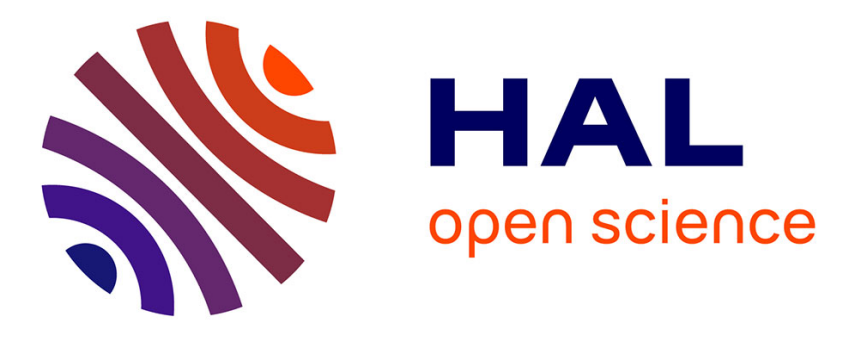

\title{
Morphological and nanostructural surface changes in Escherichia coli over time, monitored by atomic force microscopy.
}

Ibtissem Gammoudi, Marion Mathelie-Guinlet, Fabien Morote, Laure Beven, Daniel Moynet, Christine Grauby-Heywang, Touria Cohen-Bouhacina

\section{To cite this version:}

Ibtissem Gammoudi, Marion Mathelie-Guinlet, Fabien Morote, Laure Beven, Daniel Moynet, et al.. Morphological and nanostructural surface changes in Escherichia coli over time, monitored by atomic force microscopy.. Colloids and Surfaces B: Biointerfaces, 2016, 141, pp.355-64. 10.1016/j.colsurfb.2016.02.006 . hal-01342320

\section{HAL Id: hal-01342320 \\ https://hal.science/hal-01342320}

Submitted on 5 Jul 2016

HAL is a multi-disciplinary open access archive for the deposit and dissemination of scientific research documents, whether they are published or not. The documents may come from teaching and research institutions in France or abroad, or from public or private research centers.
L'archive ouverte pluridisciplinaire HAL, est destinée au dépôt et à la diffusion de documents scientifiques de niveau recherche, publiés ou non, émanant des établissements d'enseignement et de recherche français ou étrangers, des laboratoires publics ou privés.

\section{(ㅇ)(1) $\$$}

Distributed under a Creative Commons Attribution - NonCommercial - NoDerivatives 44.0 


\title{
Morphological and nanostructural surface changes in Escherichia coli over time, monitored by atomic force microscopy
}

\author{
Ibtissem Gammoudi ${ }^{\mathrm{a}, *}$, Marion Mathelie-guinlet ${ }^{\mathrm{a}}$, Fabien Morote ${ }^{\mathrm{a}}$, Laure Beven $^{\mathrm{b}}$, \\ Daniel Moynet ${ }^{\mathrm{c}}$, Christine Grauby-heywang ${ }^{\mathrm{a}}$, Touria Cohen-bouhacina ${ }^{\mathrm{a}, *}$ \\ a Université de Bordeaux, LOMA, CNRS UMR 5798, 351 Cours de la Libération, 33405 Talence, France \\ b Université de Bordeaux, INRA, CNRS UMR 1332 BFP, 71 Avenue Edouard Bourlaux, 33882 Villenave d'Ornon Cedex, France \\ ${ }^{\mathrm{c}}$ Université de Bordeaux, INSERM U1035, Bordeaux 33706, France
}

Keywords:

Atomic Force Microscopy

Gram negative bacteria

Membrane

Ageing

Lipopolysaccharide

Escherichia coli

\begin{abstract}
A B S T R A C T
The present study aims at evaluating intrinsic changes in Escherichia coli (E. coli) surface over time, by Atomic Force Microscopy (AFM). For that purpose, bacteria were immobilized on mica or on mica previously functionalized by the deposition of a polyelectrolyte multilayer cushion. AFM images reveal that E. coli population goes through different stages. Firstly, after a week, the number of healthy bacteria decreases resulting in a release of cellular components which likely become, in turn, a nutrition source for increasing the healthy population after around two weeks. Finally, after one month, most of the bacteria is dead. Our study shows a transition of a healthy rod-shaped bacterium to a dead collapsed one. Most importantly, along with the morphological evolution of bacteria, are the structure changes and the mechanical properties of their outer membrane, emphasized by AFM phase images with very high resolution. Indeed, the surface of healthy bacteria is characterized by a phase separation pattern, thereafter mentioned as "ripples". Bacterial ageing goes along with the loss of this organized structure, turning into circular areas with irregular boundaries. These changes are likely caused by a re-organization, due to external stress, of mainly lipopolysaccharides (LPS) present in the outer membrane of E. coli.
\end{abstract}

\section{Contents}

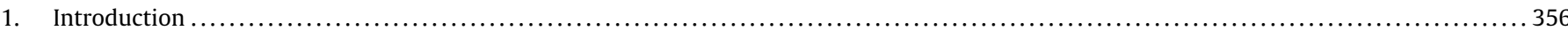

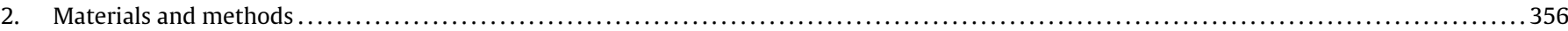

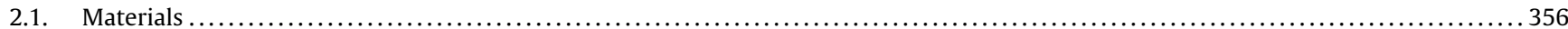

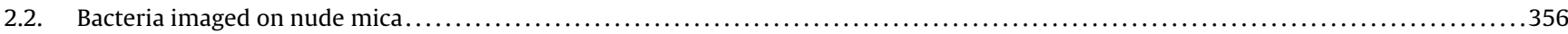

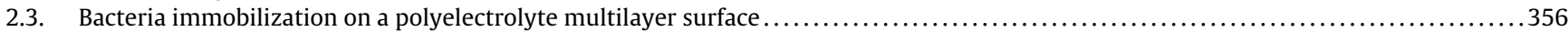

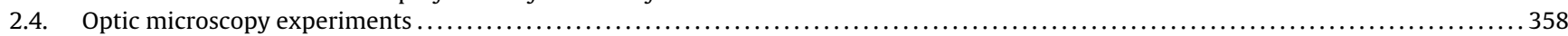

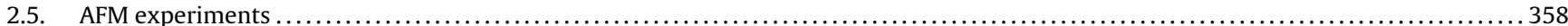

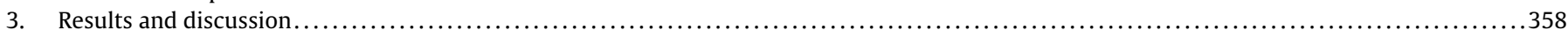

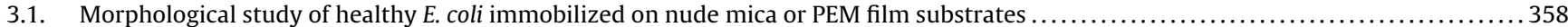

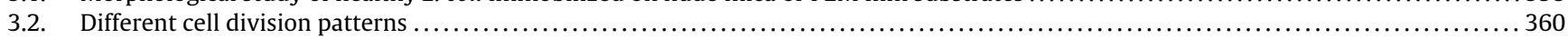

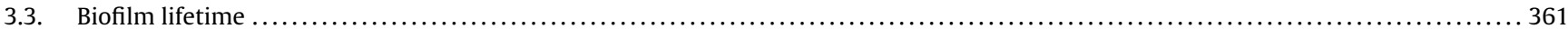

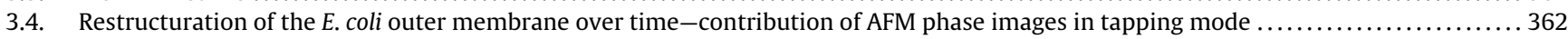

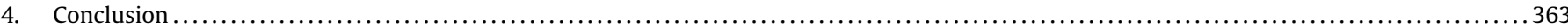

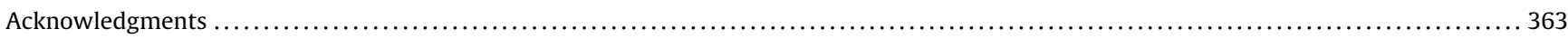

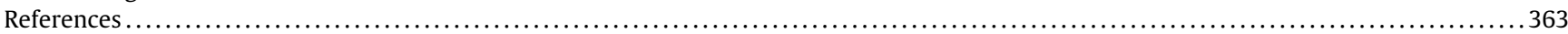

\footnotetext{
* Corresponding authors.

E-mail addresses: ibtissem.gammoudi@u-bordeaux.fr (I. Gammoudi), touria.cohen-bouhacina@u-bordeaux.fr (T. Cohen-bouhacina).
} 


\section{Introduction}

Bacterial adhesion and biofilm formation have a great interest both in natural environments and in industrial processes, biofilms being the predominant life form for bacteria to multiply and to protect themselves from environmental stresses such as UV radiation, osmotic shock and anti-microbial agents [1-4]. Bacterial biofilms undergo several stages of development from the initial attachment of bacteria to detachment and colonization of new interfaces [5].

To better understand mechanisms of such biofilm formation and bacterial metabolism inside over time, the detailed study of the biological envelop, a vital component of bacteria, might be helpful [6]. Gram negative bacteria, like Escherichia coli (E. coli), possess, along with a peptidoglycan cell wall, an outer membrane, this particular one being absent in Gram positive bacteria. This outer membrane consists of an asymmetric lipid bilayer and lipopolysaccharide (LPS) molecules as the outermost constituent, overlying a gel-like periplasm and a thin peptidoglycan layer [7]. It serves, especially LPS, as a selective permeability barrier and a protection (for instance, mutants without LPS are more permeable to mutagens) while proteins embedded or anchored to this membrane allow specific transmembrane exchanges [8]. LPS possess (i) an endotoxic part enchored to the membrane, the lipid moiety called lipid A, (ii) a long polycaccharide chain, (iii) sometimes ended by a third part pointing outwards the membrane, the $O$ chain, responsible for the bacterial antigenic specificity [9]. These extracellular sugar extensions create mutual attraction forces that curve the membrane. Part of Gram-negative bacteria's danger lies in LPS. In bacterial infections, LPS fragments from damaged bits of the bacterial walls are released locally, triggering an immune response in human organism $[7,10]$.

Consequently, investigating the structure and properties of bacterial surfaces with high resolution is of great importance to understand how biofilms behave. The ultrastructure of microbial surfaces has been extensively studied and their chemical composition and physicochemical properties have been probed, for instance, by X-ray photoelectron spectroscopy and infrared spectroscopy $[11,12]$. However, none of these techniques can provide direct information with a nanometer scale lateral resolution. Because of its high spatial resolution and its ability to image in real time under physiological conditions, Atomic Force Microscopy (AFM) has been used more and more frequently in biological field [13]. Indeed, AFM, as a scanning probe technique, is ideally suited to study surface properties of biological systems, such as bacteria, from topographical to nanomechanical properties, including composition and adhesion $[13,14]$. The non intrusive tapping mode is particularly interesting for those fragile systems as phase imaging gives access to physico-chemical properties of sample surfaces at the local scale to hundreds of $\mu \mathrm{m}^{2}$.

In this work, we probed the surface structure of $E$. coli using AFM in tapping mode. Bacterial populations were followed over a month to determine their viability. More precisely, morphological and mechanical properties of $E$. coli bacteria, especially the outer membrane ones, were investigated with high resolution, revealing fine details of its structure. We also showed that this specific organization underwent major changes with time, corresponding to modifications of the intrinsic behavior of LPS molecules. These changes allow for a rapid and accurate quantitative discrimination between viable and dead bacteria. Moreover, we proceeded with AFM, for the first time, in a complete study on E.coli bacteria: different cell divisions patterns, bacteria population organizations, morphology and rheology evolution were observed in real time.

\section{Materials and methods}

\subsection{Materials}

Gram negative E. coli bacteria (MRE 162 strain) were a kind gift from the Centre d'Etudes du Bouchet, DGA (Direction Générale de l'Armement, France). Bacteria were grown on a solid Luria medium and incubated for $16 \mathrm{~h}$ at $37^{\circ} \mathrm{C}$. After scraping, bacteria were suspended in purified water $(\mathrm{pH} 5.5$, resistivity $>18.2 \mathrm{M} \Omega \mathrm{cm})$ and placed in $1.5 \mathrm{~mL}$ microtubes for a centrifugation at $3000 \mathrm{~g}$ for 20 min. Cells were then washed twice with purified water and adjusted to $10^{8}$ cells $/ \mathrm{mL}$.

Mica, purchased from Electron Microscopy Sciences, was used for all AFM measurements and images. With an average roughness of $0.3 \mathrm{~nm} / \mu \mathrm{m}^{2}$, it is one of the best substrate to work with if one wants to get free from the substrate roughness.

\subsection{Bacteria imaged on nude mica}

Freshly cleaved mica is appropriate when imaging in air, as bacteria will not be submitted to a fluid flow. As mentioned above, mica has also a homogeneous surface which allows discriminating any topographic contrast. A $5 \mu \mathrm{L}$ droplet of bacteria suspension was directly applied on the mica and left to dry under a desiccator. To avoid aggregation and the presence of non-fixed bacteria, the sample was then rinsed with ultrapure water before imaging (Fig. 1a). Consequently, this process led to more frequent isolated bacteria and, thus, was preferred when a detailed study of the bacterium was required. For over-time experiments, we kept samples either under the AFM setup, protected from dust, to follow the same population at each step, or under a desiccator to check their general behavior over time.

\subsection{Bacteria immobilization on a polyelectrolyte multilayer surface}

To image in liquid medium or to study the morphological and rheological changes over time, we needed to immobilize bacteria on the substrate. To do so, alternative polycationic/anionic treatment of the substrate was previously used successfully [15]. Indeed, Layer by layer ( $\mathrm{LbL}$ ) self-assembly is one of the most versatile techniques to make multilayer composite films. It consists in sequential depositions of oppositely charged solutions of polyelectrolytes (PE) to form, in an inexpensive and easy way, a self-assembled molecular multilayer [16]. Biological applications are numerous; among them, worth mentioning is the immobilization of biological systems (such as DNA, proteins, enzymes or cells) and the production of multifunctional nano-scaled structures and materials [17]. This method was successfully applied in one of our previous AFM study [15].

PE considered in this work are cationic poly(allylamine hydrochlorure) $(\mathrm{PAH}, \mathrm{Mw}=56000)$, and anionic poly (styrene sulfonate) (PSS, Mw $=70000$ ). They were purchased from Sigma Aldrich. PAH and PSS were dissolved in ultrapure water at a concentration of $0.5 \mathrm{~g} / \mathrm{L}$. Each PE layer was deposited through the LbL method resulting in self-assembled molecular multilayers PAH(PSS-PAH $)_{n}$ on the mica substrate. Typically, PAH and PSS solutions were alternatively deposited during twenty minutes, adsorption and rinsing steps being repeated to obtain the desired number of PE layers, forming then polyelectrolytes multilayers (PEM, Fig. 1b). In this work the last layer was made of positively charged $\mathrm{PAH}$ to guarantee the fixation of negatively charged E. coli bacteria (Fig. 1b). As for the direct drop-off, $5 \mu \mathrm{L}$ of bacteria suspension was deposited on the functionalized mica and left to dry under a desiccator before imaging. Consequently, we applied this PEM technique to immobilize bacteria on the substrate in order to prevent their potential shift 
a)
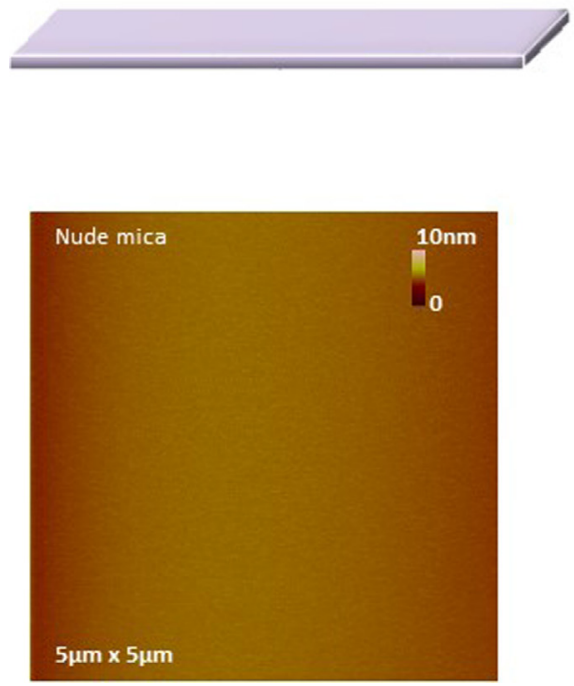

b)

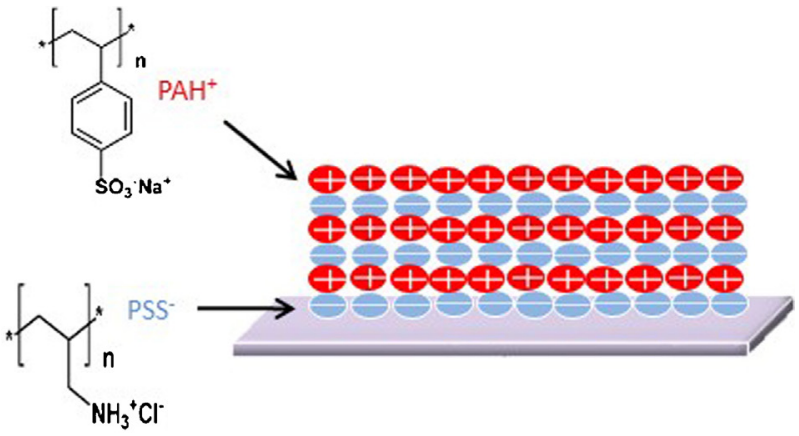

Fig. 1. Schemes and associated AFM topography images of the surfaces of nude mica (a) and mica recovered by PEM (b).

a)

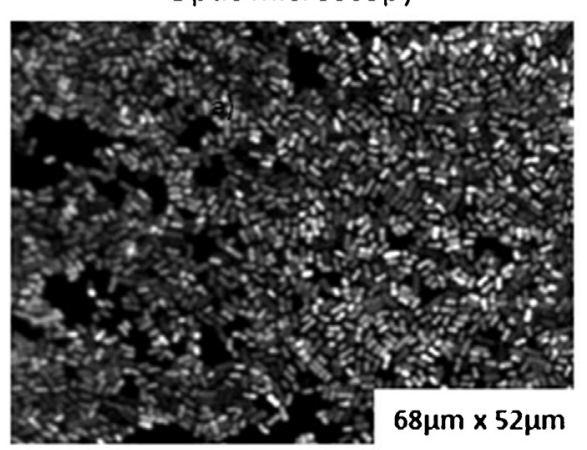

AFM 2D - topography

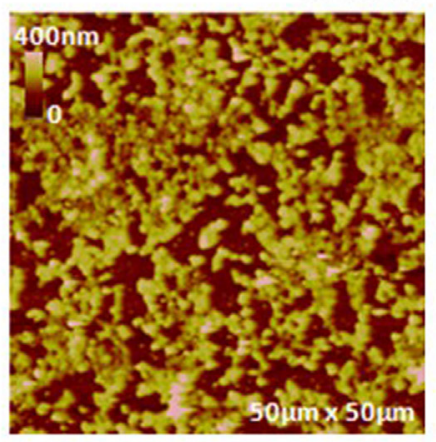

AFM 3D - topography

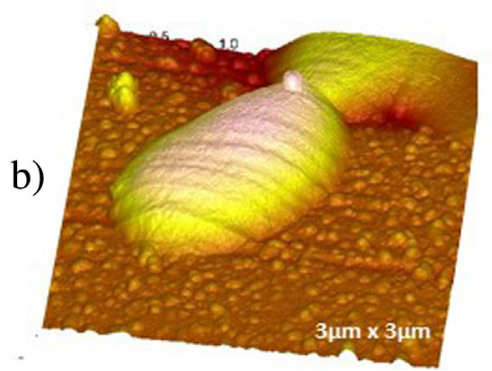

c)
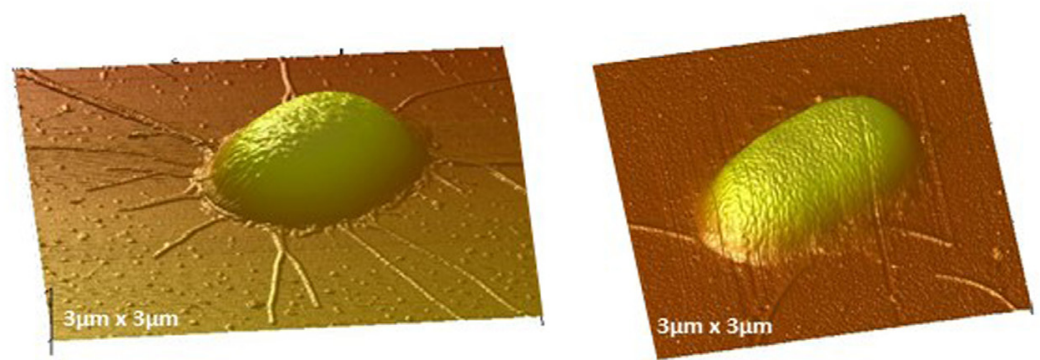

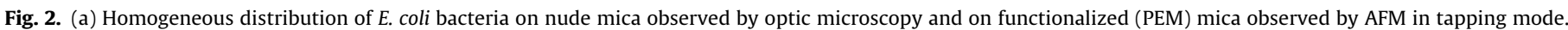

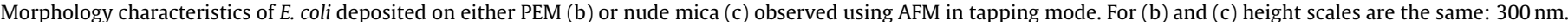
Pili and flagelles are rarely observed still attached to the bacteria because of their fragility. 
under the AFM tip. It was thus privileged for population and overtime studies. For the later, samples were conserved in the same way as for experiments on nude mica.

\subsection{Optic microscopy experiments}

For optical microscopy imaging, we used a fixed-stage upright microscope (BX51WI from Olympus) equipped with a $100 \mathrm{~W}$ mercury lamp (U-LH100HG), a BX-RFA illuminator and a LMPF1 $\times 100$ objective. Several images were taken to ensure the homogeneity of the sample and recorded using a ORCA-Flash 2.8CCD camera from Hamamatsu (Japan) and the HCImage Live V3.0 software. The lateral resolution of our setup is in the 0.4-0.6 $\mu \mathrm{m}$ range.

\subsection{AFM experiments}

AFM experiments were carried out with a Bioscope II mounted on an IX71 Olympus inverted optical microscope and operating with the NanoScope V controller and also with a Multimode AFM (Veeco-Brucker, Santa Barbara, CA). This technique is based on the detection of small forces existing between a tip and an object (the surface sample) which is scanned along the tip with a piezo scanner (maximum XYZ scan range of $150 \mu \mathrm{m} \times 150 \mu \mathrm{m} \times 12 \mu \mathrm{m}$ ). The tip is attached at one end to a cantilever which is "built in" at the other end. This technique can generate information on surface topography and mechanical properties at the nanometer level.

The AFM measurements were performed under ambient conditions (air) to get advantage of the harmonic oscillator behavior of the AFM cantilever. This operating mode involves very small forces that prevent indentation of bacteria by the AFM tip avoiding changes in the observed contrast or damage to the bacteria cells. Although imaging of bacteria under physiological conditions would make more sense, such process lowers the resolution and thus subtle details on the outer membrane we are interested in became unresolved. Anyway, ambient environment is believed not to affect bacteria which are still viable under such conditions [18].
All data presented in this paper were generated with cantilevers whose spring constant was about $40 \mathrm{~N} / \mathrm{m}$ and at a scan rate of $0.5-1 \mathrm{~Hz}$. For each experiment achieved in this tapping mode, three images were recorded at the same time: trace height, trace amplitude (signal error) and phase images. The former gives information on the topography and morphology of the system, the second emphasizes the edges and the latter allows for mechanical properties investigation. Amplitude images will be used as they increase contrasts and emphasize details. These images provide additional information on cell morphology modifications, in particular those corresponding to small changes not visible in the topographic images (height images) which are saturated due to the importance of the sample size. Phase images (phase difference between the exciting signal and the response of the cantilever) are very sensitive to the interaction between the AFM tip and the studied surface and can be linked to dissipative process allowing the study of the mechanical properties of bacteria membrane at the local scale.

Finally, to access the true topography of samples without being biased by mechanical information in height images, we worked with relatively high oscillation amplitudes to remain in the repulsive dominant mode [19,20].

\section{Results and discussion}

In this section, we will first investigate with AFM in tapping mode the morphology of $E$. coli bacteria and the organization of its population. Based on these results, we will then follow the evolution of $E$. coli with time (over a month), mainly its morphological and structural changes, to determine its viability. Finally, we will focus on the re-organization of the external membrane of $E$. coli.

\subsection{Morphological study of healthy E. coli immobilized on nude mica or PEM film substrates}

Before starting the study on the evolution of bacteria population, we first investigate the interaction between the substrate and E. coli surface. Bacteria are deposited on either nude mica or a)

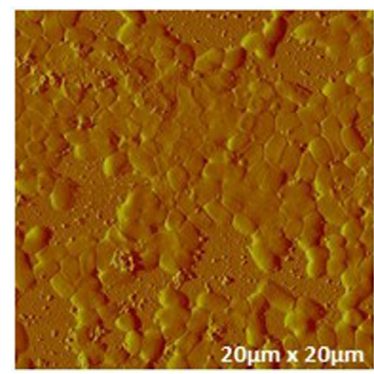

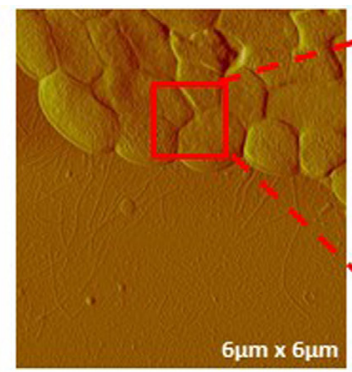
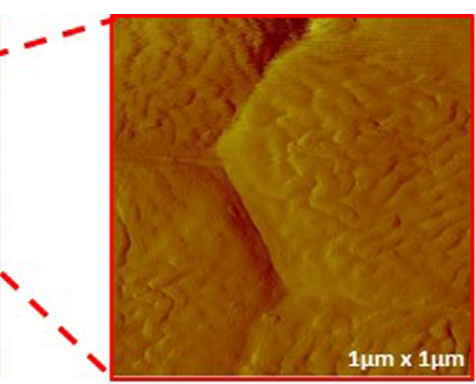

b)

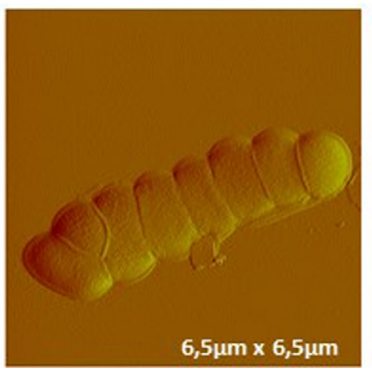

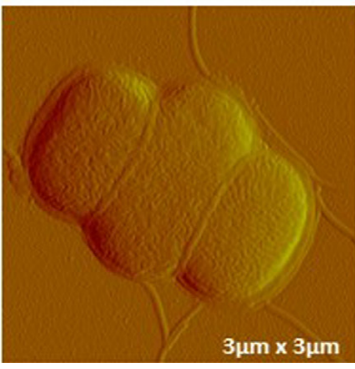

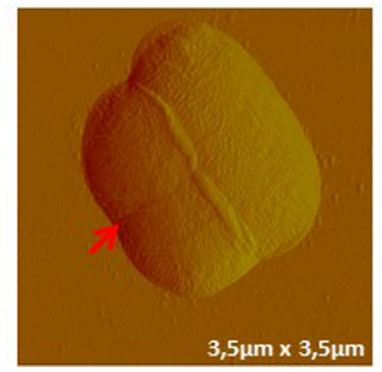

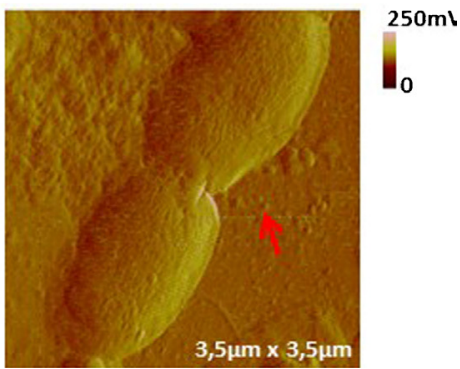

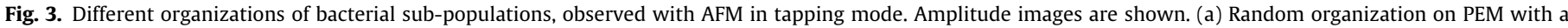

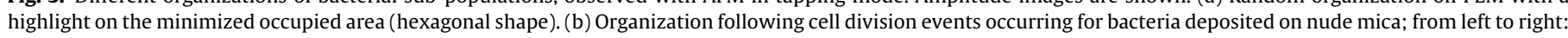
single file, side by side and an emphasize on the septum during cell division and bridge across two bacteria. 
Do

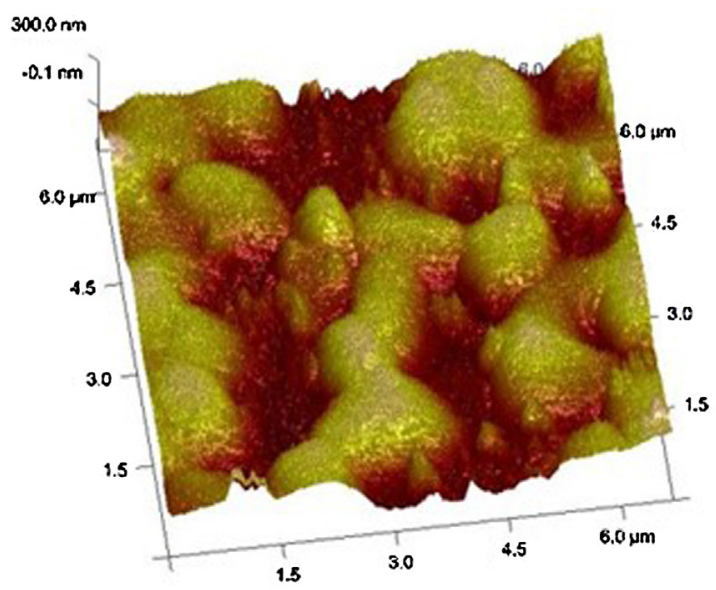

D7

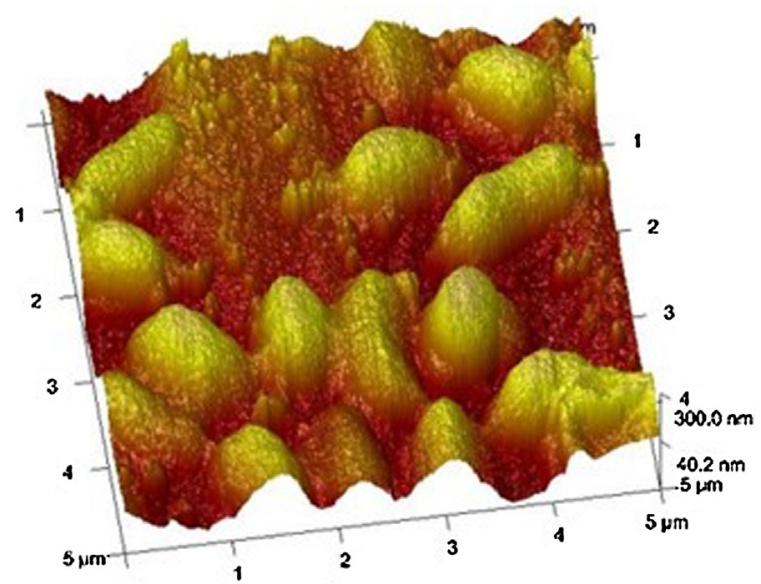

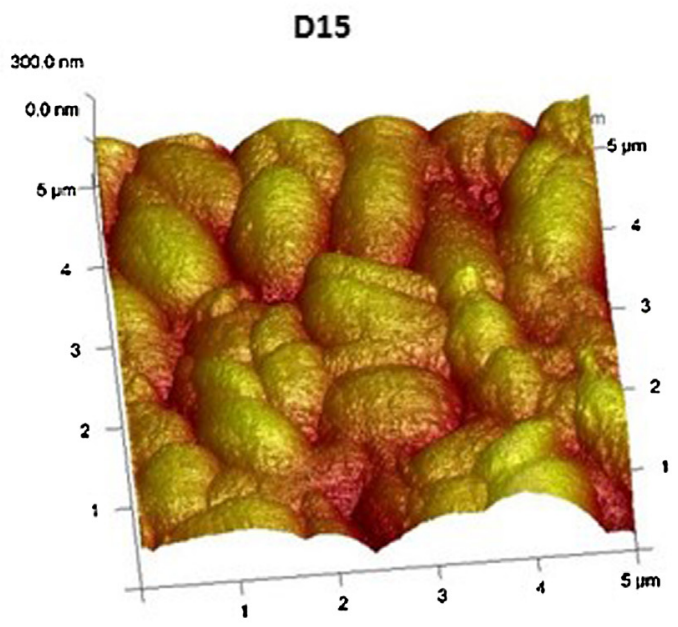

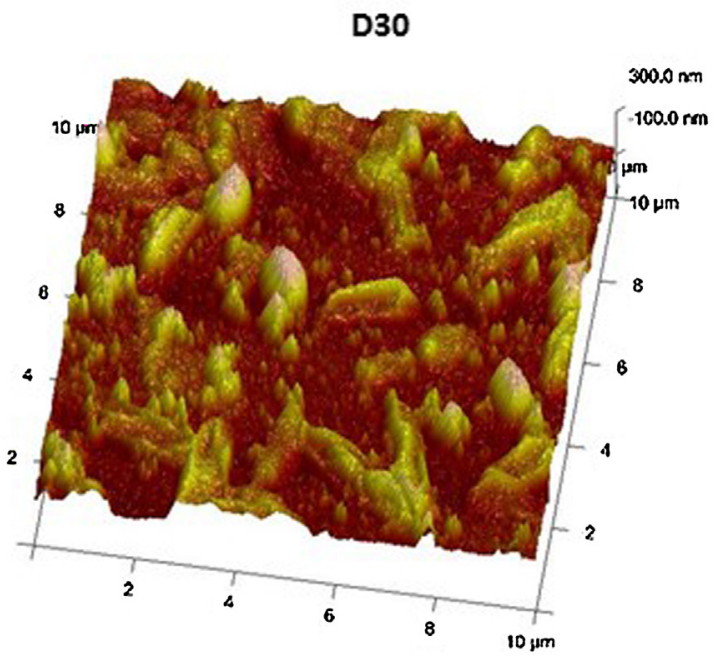

Fig. 4. AFM topographic images in tapping mode showing the evolution of E. coli population on a PEM-mica substrate over a month (D0: first day D7: after a week, D15: after two weeks and D30: after a month).

a)

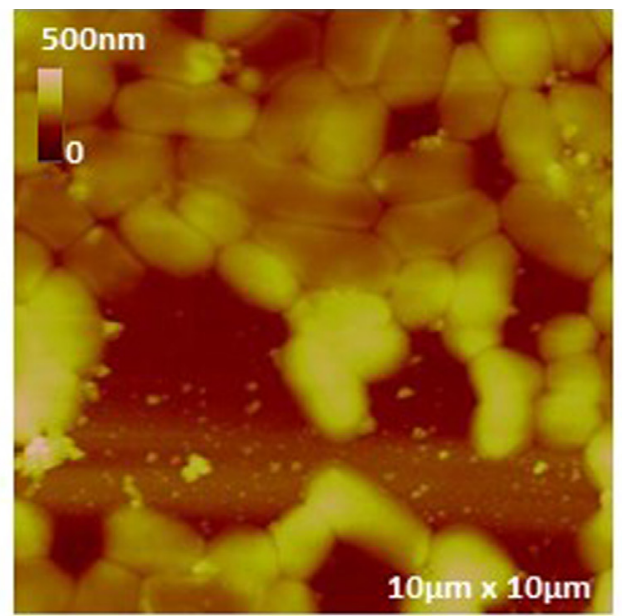

b)

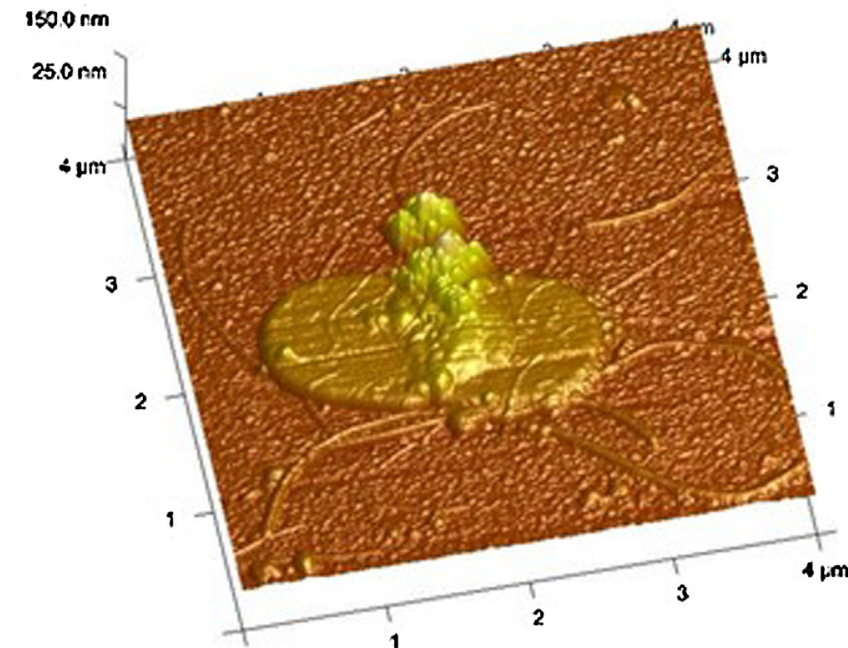

Fig. 5. Loss of membrane integrity for some E. coli bacteria after 7 days on PEM. (a) A topographical overview of the population after 7 days; (b) $3 D$ topography of a bacterium releasing its components on the substrate, resulting in the collapse of the cell. 
Topography

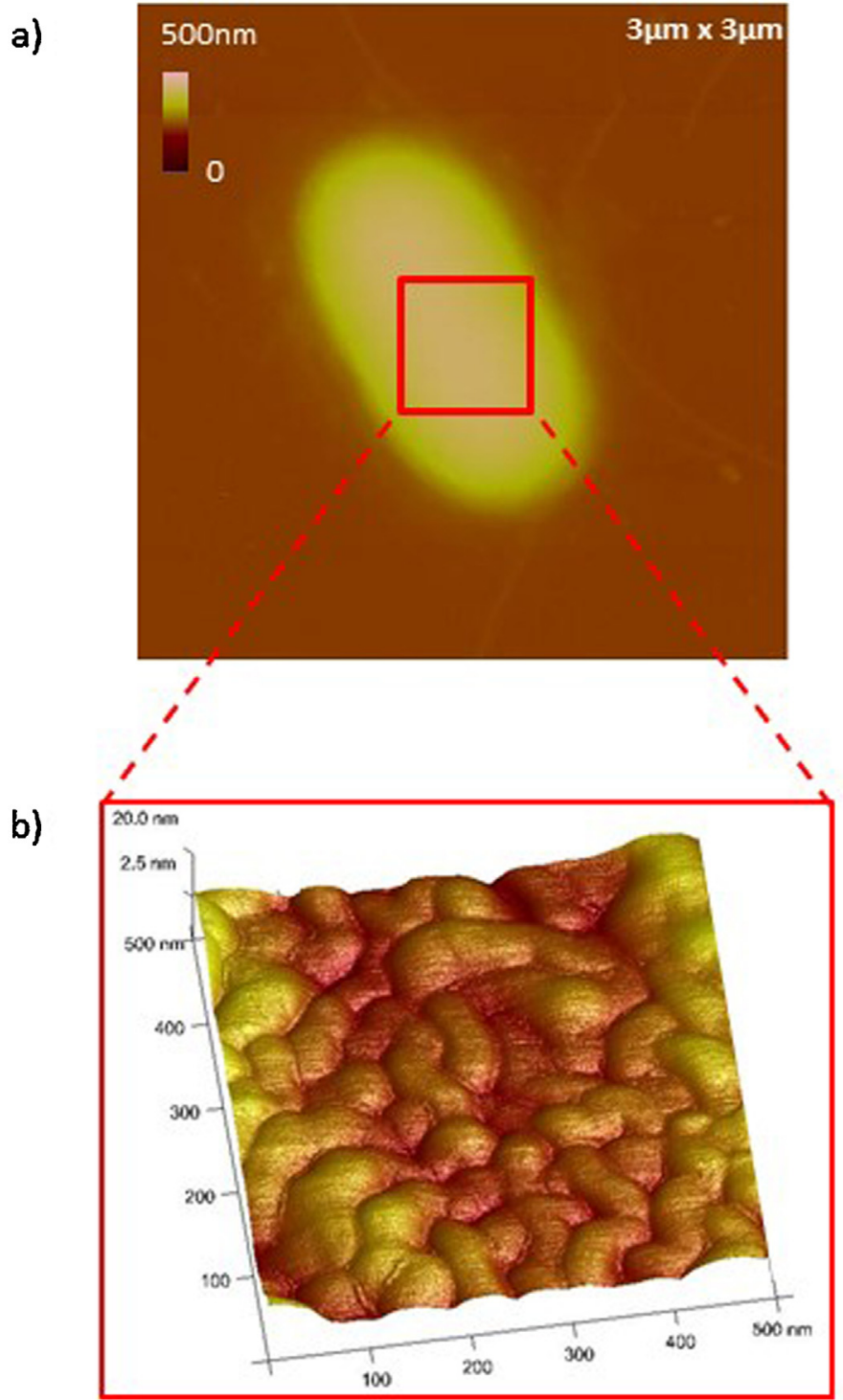

Phase

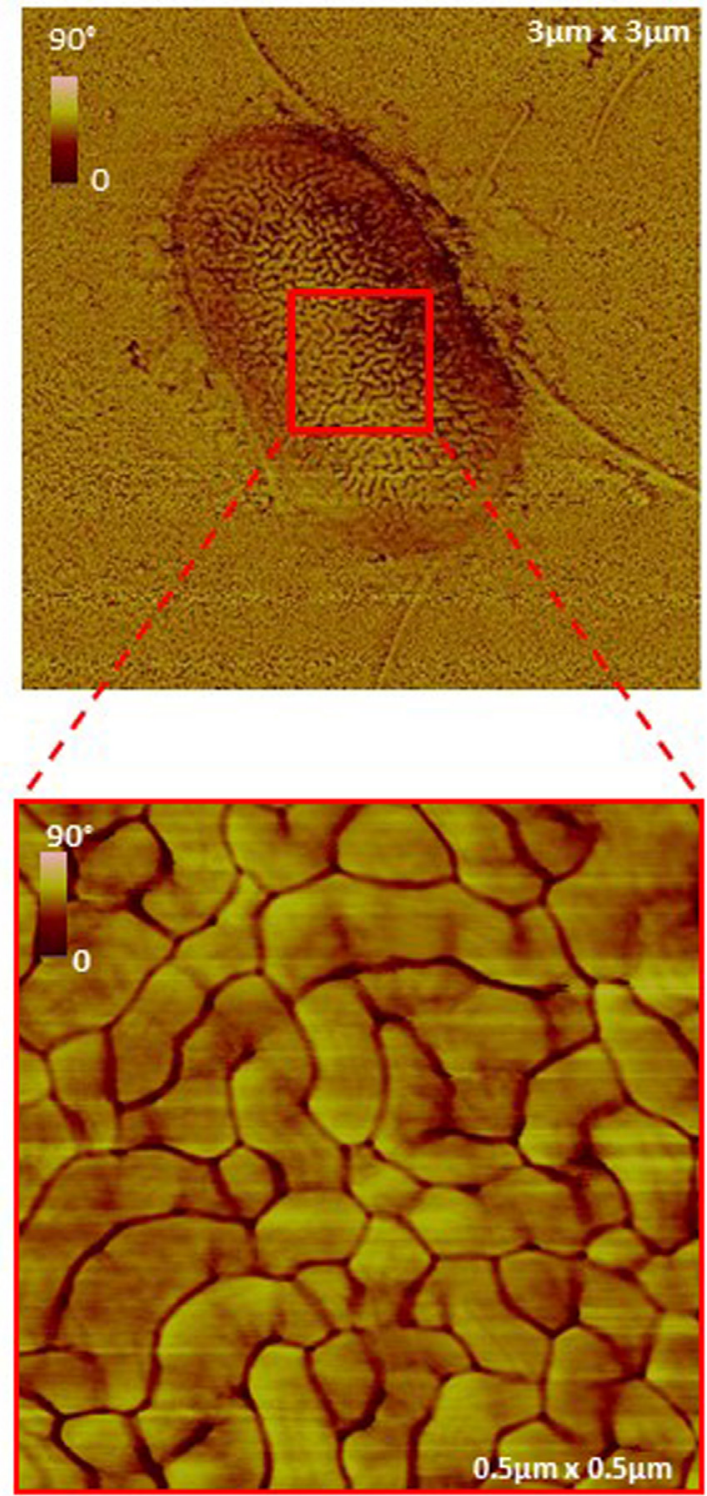

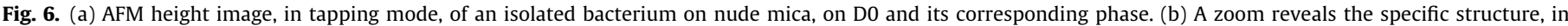
"ripples", of the outer membrane of E. coli: height image and the corresponding phase.

mica functionalized with PEM, both being studied just after samples preparation. In the later process, the surface is formed of a smooth multilayer of polyelectrolytes, sometimes composed of aggregates (Figs. $1 \mathrm{~b}$ and $2 \mathrm{~b}$ ).

Images obtained in air, on nude or functionalized PEM mica, show a homogeneous and dense layer of bacteria (Fig. 2a). This is possible thanks to the optimization of experimental conditions, mainly the bacteria concentration and drop-off process. As mentioned in Section 2, a suspension of $10^{8}$ cells $/ \mathrm{mL}$ is deposited on the substrate which is, in turn, rinsed after 30 min to keep only the fixed bacteria on the surface. Optic microscopy image (Fig. 2a) reveals rod-shaped bacteria close to other ones, though some are isolated. A large scan in AFM (Fig. 2a) confirms the formation of such a dense layer of bacteria.

Characteristics of bacterial morphology can be exploited thanks to AFM height images. The first striking feature is the rod bumped shape of E. coli (Fig. 2b and c) and its "textured" irregular membrane (Fig. 3a, Image $1 \mu \mathrm{m} \times 1 \mu \mathrm{m}$ ). It is also worth mentioning the pres- ence of flagella and pili, despite their fragility, in some observations (Fig. 2c). The estimated length (L), width (W) and height (H) of E. coli observed in air are $2.0 \mu \mathrm{m}, 1.2 \mu \mathrm{m}$ and $300 \mathrm{~nm}$, respectively. These values can vary in quite a narrow range among bacteria, notably the height, which strongly depends on the environmental experimental conditions (imaging in air or liquid), but are consistent with other results [18].

Whatever the process of deposition is (on nude mica or on PEM), morphological properties of $E$. coli do not change and cells are organized in the same way. The only difference arises from the immobilization guaranteed by PEM, which favors dense bacteria population and less isolated cells than for experiments on nude mica.

\subsection{Different cell division patterns}

The present study highlights different types of cells within the bacterial population, some of them resulting from a recent divi- 
a)

Amplitude b)

Phase
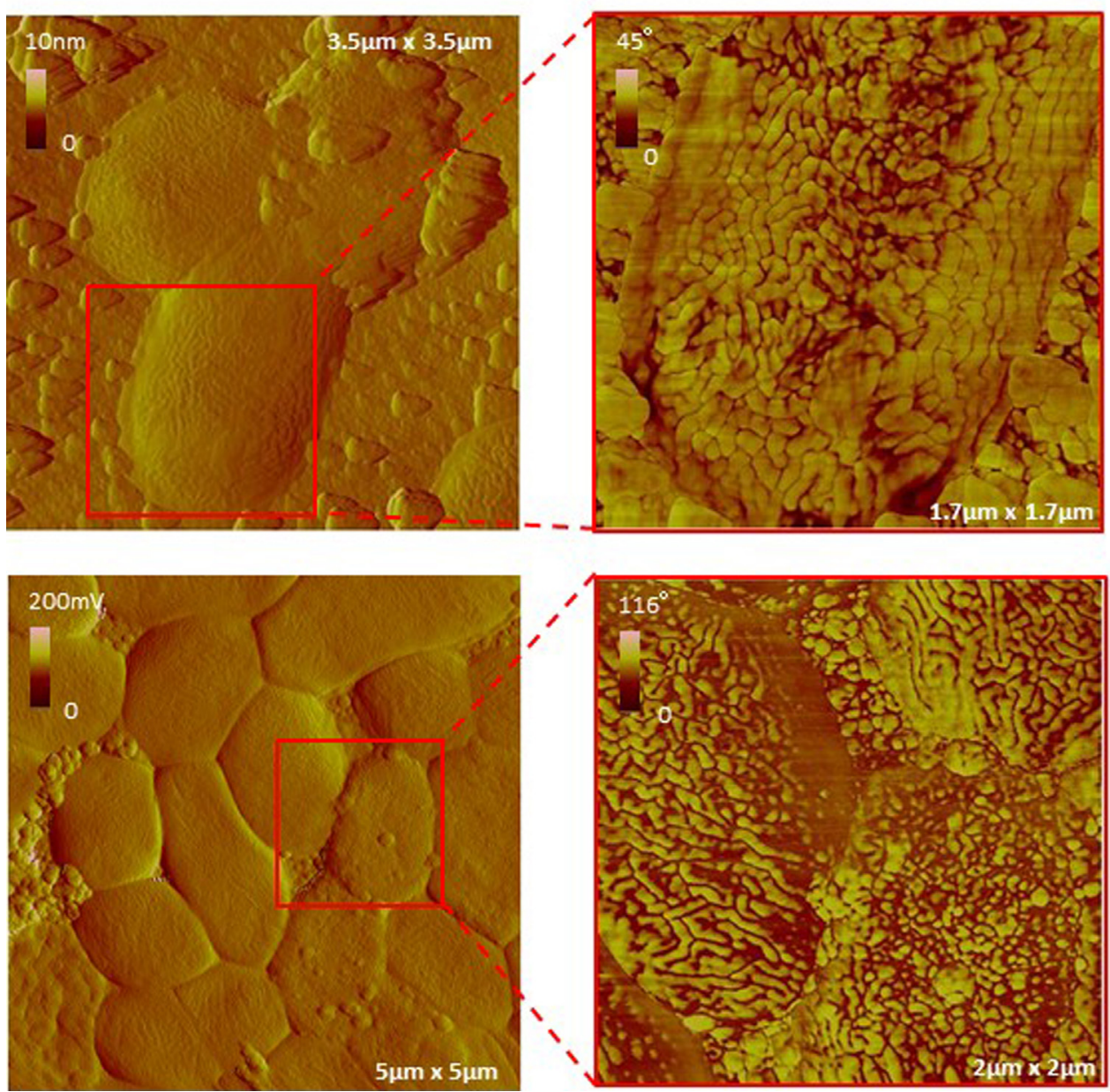

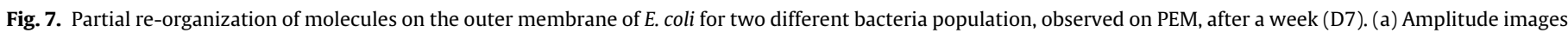
and corresponding zooms in phase images (b) on weakened bacteria.

sion, as bacteria are still alive when observed by AFM. Also, cellular processes like growth or division can occur in real time.

Bacteria are either randomly organized (Fig. 3a) or specifically distributed (Fig. 3b) on the substrate. In the first case, they are mostly packed close one to another in a way that the occupied areas are minimized. This results in a hexagonal shape of each cell. In the second case, bacteria organization depends on cell division. In particular, $E$. coli in a single file or side by side are observed (Fig. 3b), such organization being potentially explained by cell division events. Indeed, E. coli grows and reproduces, for instance, by dividing in the middle, resulting in a new pole and an old one [21], as illustrated in Fig. 3b (septum). Other patterns of cell division, along diverse planes, perpendicular or not, regularly or not, can be observed with AFM. If the division is occurring in a unique plane, a septum is observed; otherwise, one can assume that it results in a specific arrangement of bacteria, side by side and grouped in 2-8 cells (Fig. 3b). Bacteria during and just after division are smaller in terms of length and width but are as high as full grown bacteria, resulting in a more spherical than rod shape. This spherical shape is only observed for these bacteria, which are still attached; bacteria alone were always rod-shaped. Moreover, in some cases, it is possible to see links between bacteria (right image in Fig. 3b) that may allow transfer of cellular material from one cell to another.

\subsection{Biofilm lifetime}

PEM are used to keep E. coli bacteria immobilized on the substrate $[15,22]$ over time and to get a stable biofilm. Evolution of the shape, surface morphology and size of bacteria are investigated by AFM over a month. The first experiment is performed on the day after bacteria deposition (D0), then after 7 (D7), 15 days (D15) and a month (D30). The whole study on bacteria ageing was made 4 times independently, and at least 3 different areas were observed on each sample.

Fig. 4 shows typical images of bacteria population over time, from which first qualitative observations can be deduced. After the first day, bacteria cover most of the surface and are mostly in rod shape. Seven days later, the covering density surface evolves. Indeed, the topographic contrast is slightly lowered compared to D0, as for some bacteria, cell integrity is questioned: changes in cell shape and size appear. While the majority of bacteria are still high and rod-shaped, a minority collapses and exhibits a rather spherical shape. Surprisingly, 15 days later, area occupied by bacteria highly increases compared to D7. Finally, after a month, mostly dead bacteria cover the substrate. These E. coli are characterized by a complete collapse of their envelop: only the external edges remain high. 
2D - Topography

a)

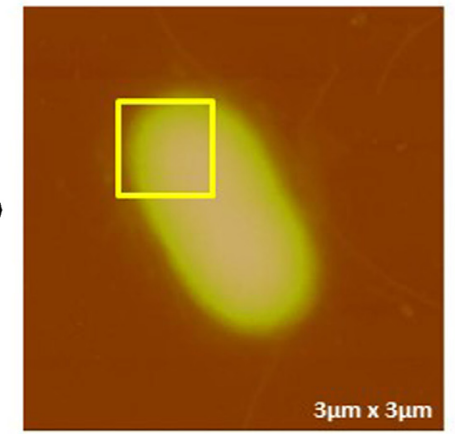

b)

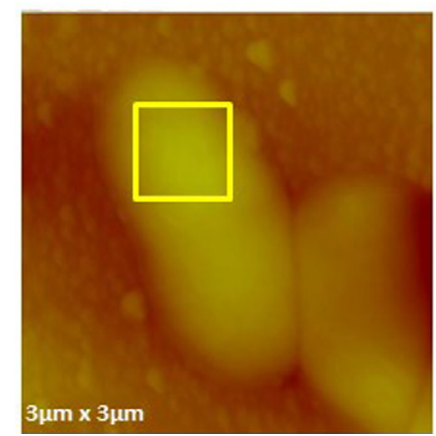

3D - Topography
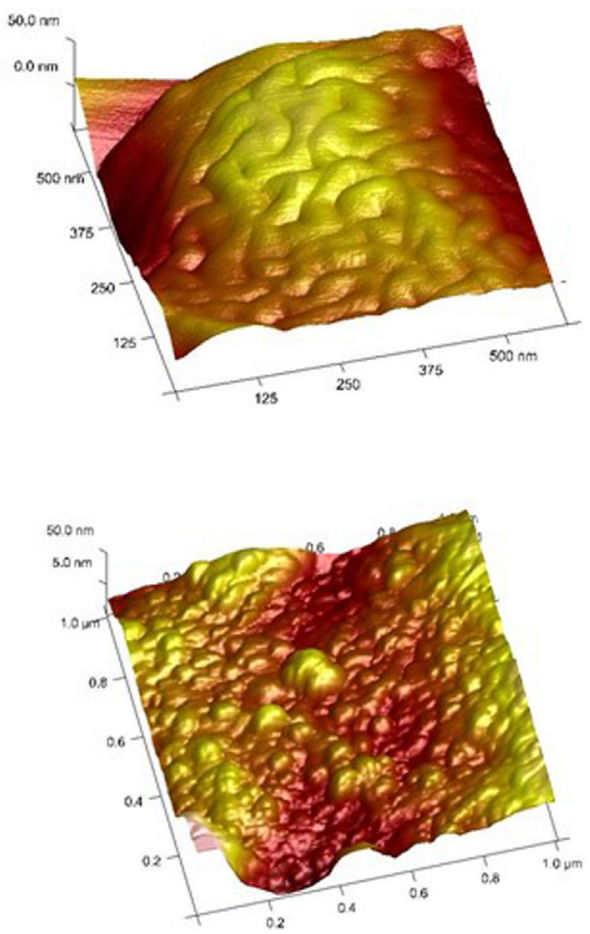

Phase
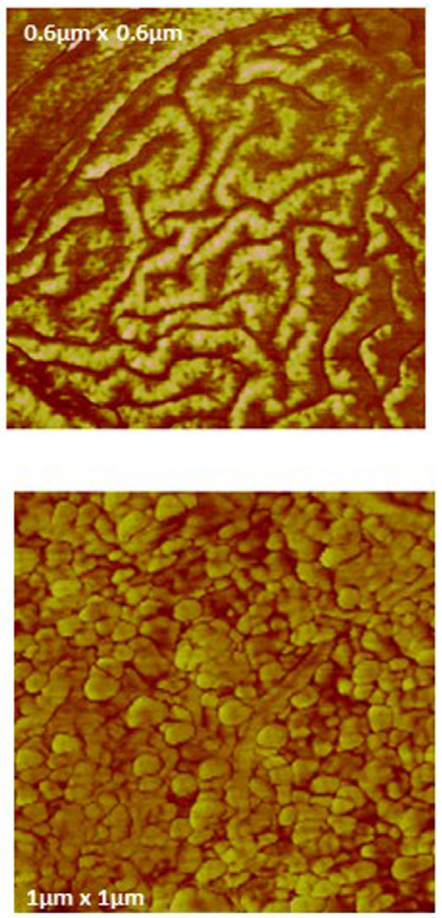

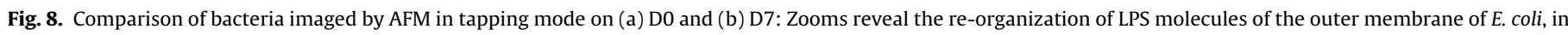
aggregates instead of “ripples". 2D height images (scale: $500 \mathrm{~nm}$ ), zooms in 3D and their corresponding phase images (scale: $45^{\circ}$ ) are presented.

Despite unfavorable conditions, i.e. no external source of nutrients, the dense film and even the growth and multiplication of bacteria at D15 lead us to assume that materials released by dying bacteria at D7 (Fig. 5) might act as an intrinsic nutrition source for the weakened cells. Even with this nutrient alternative, bacteria end up mostly dead after a month. This might be explained (i) by the lack of sufficient amounts of nutrients which stops the bacterial metabolism, (ii) by dehydration or (iii) by the production of toxins by some $E$. coli cells. Further experiments will be needed to check these assumptions out.

We did not note in our images any sign which could reveal changes in the EPS organization at the surface of E. coli bacteria, and which could confirm that these molecules are a potential nutrient source. It is rather unlikely that bacteria used EPS as nutrient source, since it would imply for them to break some specific bounds in EPS, using enzymes which are not present in such cells. To our knowledge, there is no clear information in literature describing such phenomenon. However, sharper morphology of bacteria at D7 could be due, indeed, to a dehydration of EPS. Another explanation (which does not exclude the previous one) could be related to the fact that bacteria suffer from nutrient starvation and are probably dehydrated. It is well known that starved $E$. coli bacteria are smaller than healthy ones, especially as they are stressed being initially in exponential growth phase.

Thus the morphology of $E$. coli bacteria has been highlighted with very fine details and, this, along with all processes occurring in a cell life. Indeed, AFM height images allow for the determination of topographic characteristics of $E$. coli length around $2.0 \mu \mathrm{m}$, width around $1.2 \mu \mathrm{m}$ and height around $300 \mathrm{~nm}$.

The results shown in our manuscript are reproducible, with, on the whole, a lower contrast in the case of weakened cells having lost their typical rounded shape. However, it is difficult to obtain statistics from our images, because all cells do not age with the same "speed". Area-dependent variations can be observed, probably due to differences in the bacteria immediate vicinity in terms of nutrient concentration.

\subsection{Restructuration of the E. coli outer membrane over time-contribution of AFM phase images in tapping mode}

In addition to morphological characteristics of a soft material such as the outer membrane of $E$. coli, AFM provides rheological information at the nanometer scale. Indeed, local variations of the phase signal can be related to dissipation processes due to the interaction between the AFM tip and the E. coli membrane. But the correct interpretation of the observed contrast is a delicate point which requires, in particular, the control of tip-surface interaction, to be able to distinguish between the contributions of topography and different mechanical properties. Therefore, and in order to obtain representative topographic images, we performed experiments using rather large amplitude oscillations of the cantilever (dominant repulsive mode). In this case, if the composition of the membrane and/or the organization of membrane molecules are homogeneous, the corresponding phase images should not show any contrast. This is not the case with the results obtained in this study.

Fig. 6 shows an isolated bacterium, imaged after its deposition, and a zoom on its membrane. The first striking feature is the $E$. coli external surface outer membrane structure, which is mainly visible thanks to AFM phase. Indeed, one can clearly see a phase separation pattern with "hills and valleys", composed of different materials having specific mechanical properties as shown in phase image (Fig. 6b). Another important observation, that can be made in particular in the zoom (Fig. 6b), is that the contrast of the phase images is consistent with that of the corresponding topographic ones. The same structure of the membrane with well-defined nanodomains 
is observed in phase image, these domains appearing brighter than their edges. The difference in mechanical properties between the different areas is probably responsible for the observed phase contrast, which suggests a different composition and/or a different molecular organization between the two areas (dark and bright). For example, the phase contrast should be as well in the case of a sample composed of different species (elastomer and glassy type) or a mixture of components with different organizations (rigid and fluid). The clearest areas would be the more organized/rigid ones, whereas darker ones would correspond to medium/soft ones.

The typical structure in nanodomains is referred as "ripples" thereafter. The high lateral resolution of AFM allows getting the dimensions of these linear structures. Their shape is not exactly constant but we estimate their width to be in the range [20-50 nm], their height in [2.5-5.0 $\mathrm{nm}$ ] and their length up to several microns. These estimations are in agreement with a previous study [23], stating that these large observed ranges are probably due to the number of O-units present in LPS. In between these "ripples", soft material is found compared to that within the structure which is, hence, stiffer. These structures have been already described in the literature $[24,25]$ but without identification and explanations of the phenomena.

Based on our study of bacteria evolution over time, we correlate this particular organization with healthy E. coli cells. More precisely," ripples", made of hard material, may be due to LPS, localized in the outer membrane, this structure reminding copolymers behavior [26,27]. This is not surprising as the typical polymeric behavior of these macromolecules was proved, for instance, at the air-water interface by Abraham et al. [28] who link the conformation of LPS to the lateral stress exposure. Consequently, the soft material might be the peptidoglycan layer under the external membrane of Gram negative bacteria.

After a week, this structure appears modified for some bacteria. Indeed, on Fig. 7 (top), one can observe a reduction in the value of the phase signal (increased dissipation) in the middle of the bacterium, which comes along with the loss of the "ripples" organization. Instead, molecules are arranged in small, rather spherical, aggregates, less tightly organized than "ripples" observed on the edges. A second example is shown in Fig. 7 (bottom): in the bottom right-hand corner, the bacterium exhibits this aggregate structure whereas the other two present "ripples" on their outer membrane. This rough heterogeneous surface comes along with a spread out of the bacterium and a decrease in its height. Pits in between aggregates represent soft material whereas the latter are made of stiffer material as observed in the zoom phase image. Taking into account the ageing of the sample, this specific re-structuration of LPS molecules and the decreased height are likely characteristic of a weakened E. coli. A comparison between healthy and weakened E. coli bacteria is shown in Fig. 8.

This structural evolution might be explained by the reorganization of molecules of the external membrane. As our samples are left under the AFM setup, drying occurs and no culture medium is added to reinforce bacteria. Under these circumstances, the outer membrane is the first to endure any modifications, notably in the organization of its molecules. Firstly, assembled in "ripples", ambient air could induce oxidative damage, resulting in metal depletion. According to Amro et al. [29] this depletion forces LPS molecules to re-organize and most of them are released out of the membrane. The bumps observed on our samples might be the left LPS molecules and the pits, zones where they are now missing.

In addition, when exposed to lateral stress, LPS molecules are more compact and packed together, as polymers behave [28], which explain the aggregates and the sphere-cylindrical shape observed on the surface of weakened bacteria.

\section{Conclusion}

To conclude, this study emphasizes the ageing of $E$. coli bacteria from a morphological and rheological point of view. These bacteria were found to collapse and release some of their cellular components after a week, which became, in turn, a nutrient source for weakened bacteria. Most importantly, along with the morphological evolution of bacteria, their outer membrane exhibit strong signs of re-organization with time: "ripples", characteristic of healthy bacteria, turn into spherical aggregates with irregular boundaries. These modifications are likely due to the reorganization of LPS molecules, major constituents of Gram negative bacteria external membrane, under the exposure of external stress. The understanding of how $E$. coli bacteria behave over time and in contact with a surface might help, in turn, getting deeper information on their predominant lifeform, i.e. biofilms. Indeed, our AFM study allows discriminating, in quite a simple and fast way, between alive and dead bacteria but also emphasizing the outer surface modifications of bacteria, notably the specific structure of LPS molecules.

\section{Acknowledgments}

Authors thank the Région Aquitaine and CNRS (France) for supporting this work through the equipment of the NanoSpectroImagerie (NSI-LOMA) platform used in this work (CPER COLA2). They thank also the Direction Générale de l'Armement (DGA, Ministère de la Défense, France) and the Région Aquitaine (France) for the Ph.D. grant of M. Mathelié-Guinlet.

Authors thank also NSI-LOMA platform for technical help. Bacteria were kindly provided by the Centre d'Etudes du Bouchet (DGA, France).

\section{References}

[1] L. Hall-Stoodley, J.W. Costerton, P. Stoodley, Bacterial biofilms: from the natural environment to infectious diseases, Nat. Rev. Microbiol. 2 (2004), http://dx.doi.org/10.1038/nrmicro821.

[2] J.W. Costerton, K.J. Cheng, G.G. Geesey, T.I. Ladd, J.C. Nickel, M. Dasgupta et al., Bacterial biofilms in nature and disease, Annu. Rev. Microbiol. 41 (1987) 435-464, http://dx.doi.org/10.1146/annurev.mi.41.100187.002251.

[3] H.-C. Flemming, Biofilms and environmental protection, 27 (1993) 1-10.

[4] D. Davies, Understanding biofilm resistance to antibacterial agents, Nat. Rev. Drug Discov. 2 (2003) 114-122, http://dx.doi.org/10.1038/nrd1008.

[5] G. O'Toole, H.B. Kaplan, R. Kolter, Biofilm formation as microbial development, (2000). <http://www.scopus.com/inward/record.url?eid=2-s2. 0-0033758602\&partnerID=40\&md5=f8661b28a83f24f1c170b4b411ba6ed0>

[6] S.S. Branda, Å. Vik, L. Friedman, R. Kolter, Biofilms: the matrix revisited, Trends Microbiol. 13 (2005) 20-26, http://dx.doi.org/10.1016/j.tim.2004.11.006.

[7] I.M. Szalo, B. Taminiau, J. Mainil, Escherichia coli lipopolysaccharide: structure, biosynthesis and roles, Ann. Med. Vet. 150 (2006) 108-124.

[8] D.M. Engelman, Membranes are more mosaic than fluid, Nature 438 (2005) 578-580, http://dx.doi.org/10.1038/nature04394.

[9] M. Caroff, D. Karibian, Structure of bacterial lipopolysaccharides, Carbohydr Res. 338 (2003) 2431-2447, http://dx.doi.org/10.1016/j.carres.2003.07.010.

[10] V. Meseguer, Y.A. Alpizar, E. Luis, S. Tajada, B. Denlinger, O. Fajardo, et al., TRPA1 channels mediate acute neurogenic inflammation and pain produced by bacterial endotoxins, Nat. Commun. 5 (2014), http://dx.doi.org/10.1038/ ncomms4125.

[11] P.G. Rouxhet, N. Mozes, P.B. Dengis, Y.F. Dufrêne, P.A. Gerin, M.J. Genet, Application of X-ray photoelectron spectroscopy to microorganisms, Colloids Surf. B Biointerfaces 2 (1994) 347-369, http://dx.doi.org/10.1016/09277765(94) 80049-9.

[12] U.B. Sleytr, Heterologous reattachment of regular arrays of glycoproteins on bacterial surfaces, Nature 257 (1975) 400-402.

[13] Y.F. Dufrêne, Application of atomic force microscopy to microbial surfaces: from reconstituted cell surface layers to living cells, Micron 32 (2001) $153-165$.

[14] Y.F. Dufrêne, Using nanotechniques to explore microbial surfaces, Nat. Rev. Microbiol. 2 (2004) 451-460, http://dx.doi.org/10.1038/nrmicro905. 
[15] I. Gammoudi, V. Raimbault, H. Tarbague, F. Moroté, C. Grauby-Heywang, A. Othmane, et al., Enhanced bio-inspired microsensor based on microfluidic/bacteria/love wave hybrid structure for continuous control of heavy metals toxicity in liquid medium, Sens. Actuators B Chem. 198 (2014) 278-284, http://dx.doi.org/10.1016/j.snb.2014.01.104.

[16] M. Schönhoff, Self-assembled polyelectrolyte multilayers, Curr. Opin. Colloid Interface Sci. 8 (2003) 86-95.

[17] M. Ulbricht, Advanced functional polymer membranes, Polymer 47 (2006) 2217-2262, http://dx.doi.org/10.1016/j.polymer.2006.01.084.

[18] A.V. Bolshakova, O.I. Kiselyova, A.S. Filonov, O.Y. Frolova, Y.L. Lyubchenko, I.V. Yaminsky, Comparative studies of bacteria with an atomic force microscopy operating in different modes, Ultramicroscopy 86 (2001) 121-128.

[19] L. Nony, T. Bouhacina, J.P. Aimé, Dissipation induced by attractive interaction in dynamic force microscopy, Surf. Sci. 499 (2005) 152-160.

[20] H. Nanjo, L. Nony, M. Yoneya, J.P. Aimé, Simulation of section curve by phase constant dynamic mode atomic force microscopy in non-contact situation, Appl. Surf. Sci. 210 (2003) 49-53, http://dx.doi.org/10.1016/S01694332(02) 01478-2.

[21] E.J. Stewart, R. Madden, G. Paul, F. Taddei, Aging and death in an organism that reproduces by morphologically symmetric division, PLoS Biol. 3 (2005) e45, http://dx.doi.org/10.1371/journal.pbio.0030045.

[22] I. Gammoudi, L. Blanc, F. Moroté, C. Grauby-Heywang, C. Boissière, R. Kalfat, et al., High sensitive mesoporous TiO2-coated love wave device for heavy metal detection, Biosens. Bioelectron. 57 (2014) 162-170, http://dx.doi.org/ 10.1016/j.bios.2013.12.024.

[23] L.P. Kotra, D. Golemi, N.A. Amro, G.-Y. Liu, S. Mobashery, Dynamics of the lipopolysaccharide assembly on the surface of Escherichia c oli, J. Am. Chem. Soc. 121 (1999) 8707-8711, http://dx.doi.org/10.1021/ja991374z.
[24] N. Lebedev, S.M. Strycharz-Glaven, L.M. Tender, High resolution AFM and single-cell resonance raman spectroscopy of geobacter sulfurreducens biofilms early in growth, Front. Energy Res. 2 (2014), http://dx.doi.org/10. 3389/fenrg.2014.00034.

[25] D. Greif, D. Wesner, J. Regtmeier, D. Anselmetti, High resolution imaging of surface patterns of single bacterial cells, Ultramicroscopy 110 (2010) 1290-1296, http://dx.doi.org/10.1016/j.ultramic.2010.06.004.

[26] A. Rasmont, P. Leclère, C. Doneux, G. Lambin, J.D. Tong, R. Jérôme, et al., Microphase separation at the surface of block copolymers, as studied with atomic force microscopy, Colloids Surf. B Biointerfaces 19 (2000) 381-395.

[27] F. Dubourg, G. Couturier, J.P. Aimé, S. Marsaudon, P. Leclère, R. Lazzaroni, et al., Phase-separated microstructures in all-acrylic thermoplastic elastomers, Macromol. Symp. 167 (2001) 117-137, http://dx.doi.org/10.1002 1521-3900(200103)167:1<117:AID-MASY117>3.0.CO;2-1.

[28] T. Abraham, S.R. Schooling, T.J. Beveridge, J. Katsaras, Monolayer Film behavior of lipopolysaccharide from Pseudomonas aeruginosa at the air-water interface, Biomacromolecules 9 (2008) 2799-2804, http://dx.doi.org/10.1021/ bm800562r.

[29] N.A. Amro, L.P. Kotra, K. Wadu-Mesthrige, A. Bulychev, S. Mobashery, G. Liu, High-Resolution atomic force microscopy studies of the Escherichia coli outer membrane: structural basis for permeability, Langmuir 16 (2000) 2789-2796, http://dx.doi.org/10.1021/la991013x. 